Introducción

\title{
Traición, representación y violencia en la política contemporánea
}

Diego Fernández H. *

*Universidad Diego Portales

El año 1992, Azade Seyhan publicó un estudio sobre la estética del romanticismo alemán que llevaba por título Representation and Its Discontents ${ }^{1}$. Independiente de las tesis que contiene el estudio, cualquier lector familiarizado con la obra de Sigmund Freud no puede dejar de notar la referencia apenas velada al célebre ensayo del psicoanalista vienés, que fuera publicado en 1930, con el título Civilizations and Its Discontents ${ }^{2}$. Con todo, si Freud postulaba un "malestar" inexorable a nuestra existencia en la cultura y a nuestra condición humana (pues no hay, para Freud, una forma propiamente humana de existencia por fuera de la cultura), la apuesta de Seyhan consiste en desplazar esa "fuente de malestar" -para reproducir los términos de Freud- hacia el ámbito de la representación, en todos los sentidos que ésta convoca: por lo pronto, política, estética y epistémica.

Si a la hora de tematizar el problema de la "cultura" -sobre todo en Tótem y Tabü (1913) - Freud se había basado en un amplio número de estudios etnográficos, con el problema de la "representación" ocurre algo distinto. Al decir de Heidegger, que le dedicó un examen detallado en La época de la imagen del mundo a fines de los años treinta, la representación adquiere el carácter de una "dominación sobre la totalidad de lo ente"4. En este sentido, la representación -o el régimen de la representación- define una época (la de la "imagen del mundo", nada menos) pero no es en sí misma una condición intrínseca de la existencia humana. En este sentido, no es exagerado sostener que el pensamiento de Heidegger constituye un esfuerzo por pensar la posibilidad de una emancipación con respecto

\footnotetext{
${ }^{1}$ Azade Seyhan, Representation and Its Discontents: The Critical Legacy of German Romanticism (California: University of California Press, 1992).

${ }^{2}$ Sigmund Freud, Civilization and Its Discontents. (Ontario: Broadview Press), 2015.

${ }^{3}$ Sigmund Freud, "Tótem y Tabú" en Obras Completas, vol. XIII (Buenos Aires: Amorrortu), 2008.

${ }^{4}$ Martin Heidegger, "La época de la imagen del mundo", en Caminos de bosque (Madrid: Editorial Alianza, 2006), 72 .
} 
al dominio de la representación: por eso, con relación a ella, habla de un "acontecimiento" [Geschehnis]. (Los consabidos compromisos políticos, archipolíticos, estético-políticos o "nacional-esteticistas" del filósofo de la selva negra deben leerse estrictamente como parte de este esfuerzo). Es que la representación no deja de ser un humanismo. Más aún, en la medida en que ella que ejerce dominio y (se) determina como época, ella vale también de fundamento para el humanismo que presuntamente agoniza, al igual que la época que lo aloja. Lo expresa Heidegger en un largo pasaje del ensayo del '38, del que nos limitamos a referir apenas algunas líneas:

A diferencia de la percepción griega, la representación moderna [neuzeitliche Vorstellen] tiene un significado muy distinto, que donde mejor se expresa es en la palabra repraesentatio. En este caso, representar [vorstellen] quiere decir traer ante sí eso que está ahí delante en tanto que algo situado frente a nosotros, referirlo a sí mismo, al que se lo representa y, en esta relación consigo, obligarlo a retornar a sí como ámbito que impone las normas [...]. Lo decisivo [de este proceso] es que el hombre ocupa esta posición por sí mismo, en tanto que establecida por él mismo, y que la mantiene voluntariamente en tanto que ocupada por él y la asegura como terreno para un posible desarrollo de la humanidad. Sólo a partir de este momento puede decirse que existe algo similar a una posición del hombre. [...] La época que se determina a partir de este acontecimiento no sólo es nueva respecto a la precedente a los ojos de una contemplación retrospectiva, sino que es ella la que se sitúa a sí misma y por sí misma como nueva ${ }^{5}$.

El estudio de Azade Seyhan tiene una pretensión específica, que es la de esclarecer la noción de representación al interior de los textos del romanticismo de Jena, sin hacer mayor referencia a las consecuencias políticas que se derivan de esa discusión. No obstante, en diversos pasajes el autor llama la atención sobre un aspecto fundamental que comparten ambas esferas -la estética y la política-, al punto de que ellas llegan a confundirse: mostrar que la representación (Repraesentatio, Vorstellung) hace prevalecer su estructura autónomamente respecto al contenido o al "objeto" representado. El representante que

\footnotetext{
${ }^{5}$ Ibid., 73. Destacado nuestro.
} 
representa, en otras palabras, lo hace a costa de lo representado. Éste, por su parte, queda relegado, sustituido, y en último término -cuando se trata de una vida o de una comunidad política-traicionado ahí donde algo otro (la representación y el representante) lo representa. De este modo, la tesis de Heidegger recién evocada redunda en el siguiente problema: todo cuanto se encuentra debidamente representado se encuentra, por ello mismo, "traicionado". En otros términos, el régimen de la representación es a su vez e inherentemente un régimen de traición; la presencia es el costo que la "cosa" - sea cual sea- debe pagar para acceder a la representación.

En este sentido, el texto de Seyhan actualiza una discusión que es intrínseca al despliegue de la filosofía moderna, pero que tiene una incidencia decisiva en una serie de esferas diversas, por excelencia la de la política. Cuando Derrida vuelve sobre la tesis de Heidegger, en un largo texto dedicado a examinar el múltiple trayecto traductivo de la noción (Raepresentatio, Vorstelung, Darstellung, y su retorno a las diversas lenguas romances), lo hace reproduciendo esa tesis ("lo que sería característico [de la época moderna] es la autoridad, la dominación general de la representación (...), [el hecho de que] todo lo que deviene presente, todo lo que es, todo lo que sucede (...), es aprehendido en la forma de la representación" "), a la vez que señalando los riesgos que una "salida" de dicho régimen podría acarrear (en su dimensión política, y sin apenas nombrar a Heidegger en ese pasaje, el riesgo es, desde luego el fascismo: el riesgo cierto que enfrenta nuestra época la presunta hora del cambio de mundo al que nos ha tocado asistir). Dice Derrida:

Se podría decir en otro lenguaje que una crítica o una deconstrucción de la representación resultaría débil, vana y sin pertinencia si llevase a algún tipo de rehabilitación de la inmediatez, de la simplicidad originaria, de la presencia sin repetición ni delegación, si indujese a una crítica de la objetividad calculable, de la ciencia, de la técnica, o de la representación política. ${ }^{7}$

La pregunta nuclear con que se abría la convocatoria del presente número de Pléyade movilizado, apremiado o acicateado por circunstancias sin precedentes en Chile (“octubre")

\footnotetext{
${ }^{6}$ Jacques Derrida, “Envío”, en Psyché. Invenciones del otro (Buenos Aires: Ediciones La cebra, 2017), 128.

${ }^{7}$ Ibíd., p. 129.
} 
y en el mundo ("pandemia")- era precisamente la pregunta por la posibilidad de una representación que fuese capaz de escapar de la "condena" hacia lo(s) representado(s) ${ }^{8}$. No era casual la referencia al estudio de Seyhan, en un sentido distinto a su vez al de la referencia al malestar, la "condena" o el abismo". Seyhan mostraba que -en su carácter escéptico, fragmentario, y expresamente anti-sistemático- el imaginario del temprano romanticismo alemán había consistido en buena medida en un esfuerzo por inventar una noción de representación (Darstellung) que no opera ya bajo la lógica de la duplicación, la sustitución y la tristeza -tristeza, porque lo que la representación contiene no es otra cosa que el "objeto muerto", mudo o silente-, sino una representación de hacer justicia a ese "objeto" (o a ese “pueblo”). En una dimensión estrictamente política -se advertirá el riesgo ya mencionado por Derrida-, se trataba de sostener la posibilidad de una imposibilidad: una representación y un representante que ya no sustituye y expulsa el pueblo que representa sino que -por ejemplo- lo encarna, lo constituye, lo hace aparecer como pueblo. (El momento "populista", como a veces se lo llama -pero también la amenaza fascista, no neo-fascista, sino directamente fascista- está desde luego íntimamente vinculada a esta posibilidad).

¿No es de esta índole, acaso, la querella que se escucha por doquier en las calles de Santiago, París, Hong Kong y un largo etcétera: No queremos más representación, nos queremos a nosotras y a nosotros mismos? Para remitirnos al caso chileno - a eso que, a falta de una mejor denominación, hemos convenido en llamar "octubre"- se ha repetido con

\footnotetext{
${ }^{8}$ En el ensayo Prejuzgados. Ante la Ley, Derrida propone una sugestiva conexión entre "el malestar en la cultura" y el "malestar en la representación". Esta ocurriría por vía de la Ley -por el hecho mismo de la ley; de que ella, para ser la ley, tenga por requisito su im-posición, de que toda ley, para serlo, habría no sólo de ponerse, sino de pre-ponerse, y de im-ponerse (la palabra alemana es Ge-setz subraya precisamente este problema). No es casual que el relato de Kafka se titule, en alemán, con la misma preposición (Vor) que contiene la palabra alemana "representación" (Vor-stellung). Es que Vor dem Gesetz ("Ante la ley") es la experiencia de la ley en cuanto experiencia de estar siempre "ante" una instancia mayestática inescrutable, que está velada, y que a la vez sólo puede se muestra en su velamiento y en su inaccesibilidad (ella debe hacer patente, para ser ley, que es inaccesible). Sólo accedemos a la representación o al representante (el guardián, en el relato que es apenas uno en una cadena infinita de guardianes). Por esto, sugiere Derrida, no hay tal cosa como la ley desnuda o la ley en cuanto tal (no ha hay un en cuanto tal de la ley) en la medida en que ella consiste en la re-presentación de su perpetua sustracción: "Tanto en alemán como en francés, 'Ante la ley' se entiende corrientemente como comparecencia sujeta y respetuosa de un sujeto que se presenta ante los representantes o los guardianes de la ley. Se presenta ante los representantes: la ley en persona, si así puede decirse, nunca está presente, aunque 'ante la ley' parezca significar 'en presencia de la ley'. El hombre está entonces de cara a la ley sin plantarle cara nunca. Puede estar in front of it pero no la afronta jamás". Jacques Derrida, Prejuzgados. Ante la Ley (Madrid: Editorial Avarigani, 2011): 49ss.

${ }^{9}$ Véase en este sentido el libro de George Hartley, The Abyss of Representation (Durham: Duke University Press, 2003), que examina en detalle la "respuesta" de la tradición marxiana en relación con la cuestión de la representación.
} 
sospechosa insistencia que la crisis que aqueja al "más estable" de los países de América Latina sería, en lo fundamental, una crisis política e institucional, por cuanto las instituciones de la república ya no contienen ni representan a la ciudadanía, ni mucho menos configuran un pueblo. El Gobierno, el Congreso, la Iglesia, e inclusive la propia Universidad y los saberes expertos que alberga, son instituciones -cual más cual menos- que aparecen fuertemente cuestionadas y desprovistas de legitimidad frente a las y los ciudadanos. Del mismo modo, mientras el conjunto de las instituciones va a la baja, la palabra "traición" va al alza y se deja escuchar por doquier en las calles para designar a nuestros representantes. Por la misma razón, no han faltado las comparaciones con la Argentina de 2001 ("que se vayan todos") y con la España de 2011 ("no nos representan").

A partir de una variación de aquello que Foucault entendía por "crítica" (un cierto "arte de no ser gobernado"10), el problema retorna ahora bajo la forma de un derecho a no ser representado, poniéndose al descubierto el vínculo preciso entre "representación” y "gobierno" (un vínculo que podría deducirse también de otros trabajos de Michel Foucault, como Las palabras y las cosas). Pero ¿es posible una política sin representación? ¿Es acaso posible otra forma de representación? ¿No se topa acá la imaginación (popular) con su propio límite? ¿No incuba esta extraña suerte de "neo-interdicción representativa", como ya decíamos, un germen favorable para la reedición de las peores formas de fascismo?

Los textos reunidos en el presente volumen de revista Pléyade fueron escritos en condiciones de excepción, y no sólo porque intentan pensar una situación doblemente excepcional. Para quienes escribieron desde y sobre Chile (desde "octubre") el Estado ha experimentado en lo fundamental un repliegue a sus funciones securitarias - conservación del orden- a costa de la custodia de una serie de derechos fundamentales que tiene por mandato resguardar (en lugar de vulnerar). A su vez, el "estallido" o la "revuelta"11, entremezclada con las dinámicas

\footnotetext{
${ }^{10}$ Michel Foucault, “¿Qué es la crítica? [Crítica y Aufklärung]”, Daimon Revista Internacional de Filosofía 11 (1995): 5-26.

${ }^{11}$ Para la distinción entre "estallido" y "revuelta" ver Luis Thieleman, "Notas para la historia de un desencuentro en la revuelta. Sobre alianzas sociales, izquierdas y una década de luchas sociales. Chile, 2011-2020", Revista Némesis 16 (2020): 110.
} 
propias de la pandemia (el confinamiento y una crisis económica en curso que ha golpeado duramente a los sectores más desprotegidos por el mismo Estado), configuran una situación sin precedentes en Chile. También, como antes sugeríamos, el caso chileno está interconectado con la crisis que, para bien o para mal, experimentan las democracias representativas (ese "oxímoron"12) a lo largo y ancho del planeta, pero que contiene notas específicas que exigen el reconocimiento de su singularidad, de su condición de "caso".

Sin excepción, todos los artículos reunidos en en el presente número de Pléyade piensan el problema de la representación en relación con sus límites, su fracaso, su imposibilidad, y en último término -para decirlo según los términos de Carlos Casanova en el artículo "Pueblos apare(cie)ntes. Imagen y Representación”-, con su "aporía”. Casanova refiere esta aporía a cinco dimensiones: "la unidad moderna de pueblo y representación; la expropiación material y simbólica del pueblo; la exposición de los pueblos a desaparecer; la anfibología del concepto de pueblo y la diferencia nunca del todo resuelta entre el aparecer del pueblo y su aparición". Es que, como muestra Casanova a partir de una revisión de los clásicos de la teoría política moderna - primero- y de una serie de autores contemporáneos después (Agamben, Arendt, Deleuze, Didi-Huberman, Dusso, y un largo etcétera)-, ha habido desde siempre hacia la representación política una relación de desconfianza de parte de los representados. Cada cierto tiempo, aunque ininterrumpidamente, el pueblo -sea lo que sea que esta palabra quiera decir por ahora, aunque siempre haciendo valer una multiplicidad irreductible a la representación- "estalla" haciendo valer su multiplicidad y su irreductibilidad frente a la unidad trascendental que aquélla parece exigir. Es que "un pueblo -dice Casanova- no es otra cosa que la aparición apare(cie)nte de existencias singulares, diversas".

\footnotetext{
${ }^{12}$ Varios de los problemas desarrollados en el presente número tienen un fructífero antecedente en el vigésimo número de Pléyade, denominado "Republicanismo y democracia agonal. En la "Introducción" a dicho número, Gonzalo Bustamante señala: "Para algunos de los autores pertenecientes a las tradiciones [democráticas y republicanas radicales], conceptos como 'democracia representativa' o 'democracia bien ordenada' serían un oxímoron. Si esto es cierto, entonces el estado de derecho debería básicamente recuperar y reflejar una constante reinterpretación de sí mismo, y la economía no debería estar sujeta a leyes abstractas del mercado sino al sistema de necesidades establecido por los propios ciudadanos. Desde este punto de vista, una característica esencial de lo que se denomina "neoliberalismo" y de su condición anti-democrática radicaría en la búsqueda del predominio sistémico de la lógica del mercado en la economía y del de la administración (entendida como decisión) en el sistema político, por sobre la posibilidad del juicio racional y colectivo, sin determinación previa alguna, que son propios del poder constituyente democrático". Gonzalo Bustamante, "Republicanismo y democracia agonal: una presentación genealógica. Introducción”, Pléyade 20 (2017): 26.
} 
En una línea similar, aunque especialmente a través de un examen crítico de una pléyade de autores contemporáneos (Foucault, Deleuze, Žižek, Arendt, Badiou, etcétera), Carlos Garduño profundiza en la tensión entre la unidad de la representación y la multiplicidad de los colectivos: cómo pensar una representación que sea capaz de acoger esta variabilidad en lugar de quedar capturada en las aporías antes mencionadas (a mayor universalidad de la representación -sostiene Garduño, parafraseando a Žižek-, mayor a su vez la potencia de exclusión que ella contiene). La "salida" - si se trata de tal cosa- que Garduño propone estaría dada por el mismo filósofo eslavo en su crítica a Badiou: "El acontecimiento es un inexistente: no tiene existencia positiva y solo puede referirse negativamente $[\ldots]$ como 'singular universal', un elemento que participa en el universal (pertenece a su mundo), pero carece de un lugar determinado en él".

El último artículo en esta línea, el de Martín Chicolino, vuelve también sobre el problema de la representación, restringiendo su foco a tres autores fundamentales: Deleuze, Guattari y Foucault. Luego de exhibir la dependencia entre el concepto moderno de "persona jurídica" (o "sujeto de derecho") y el de representación, el artículo vuelve sobre una de las "alternativas" que la política moderna ha (re)encontrado para hacer frente a la aporía de las democracias liberales, "que sigue siendo la base de nuestras actuales formas de gubernamentalidad”. “¿Por qué no podríamos nosotros -pregunta Chicolino-, por nosotros mismos (sin representantes indirectos), ejercer un poder y una autoridad colectivos?" La respuesta mayoritaria pero no unívoca que la tradición política moderna habría dado a esta pregunta, prosigue el autor, es la ignorancia del pueblo: su incapacidad de saber aquello que mejor le conviene. La idea de una democracia directa se habría convertido en una interdicción o en un escándalo para el pensamiento político moderno. A partir de una aguda lectura de los filósofos antes mencionados, Chicolino se detiene y pormenoriza en este escándalo. Es que la representación -dice el autor, citando un pasaje de Deleuze- "provoca risa". En su ambigüedad (burla y alegría) parece necesario hoy más que nunca la experiencia de esta carcajada.

El artículo de Pablo Oyarzún -que tiene en su origen una conferencia pronunciada en la Universidad de Southern California- es con probabilidad la contribución que con mayor énfasis se refiere al caso chileno, reparando en dos fenómenos que lo han acompañado fáctica o interpretativamente: el miedo y la violencia. Cualitativamente distinto del de la dictadura, 
aunque igualmente "intenso, corrosivo, lascerante" ("la amenaza constante de no poder solventar el cúmulo de deudas e intereses" que está a la base del "modelo" chileno), el miedo se nutre la necesidad de "seguridad", dice Oyarzún, teniendo constantemente a Hobbes a la vista en sus elaboraciones. Por su parte, y antes que una mera consigna exhortando a saltar los torniquetes del metro de Santiago, "evade" constituye, a los ojos de Oyarzún, una "reivindicación en acto", una suerte de llamado del pueblo a sí mismo, incluso si éste carece de toda "mismidad" a la cual volver, por cuanto su modo de comparecer es siempre "espectral", constituyéndose como tal en ese llamado y en el conjunto de prácticas en el que él aparece. La dimensión espectral -por fuera de la representación, entonces, aunque no por fuera de las imágenes (en plural) y de la puesta en escena de los cuerpos en el teatro de una ciudad disputada y carnavalizada- implica que esa comparecencia del pueblo no pueda ocurrir sin un grado de "violencia", porque todo cuanto ocurre por fuera de la representación (esa unidad trascendental) ocurre de golpe, desafiando las coordenadas preestablecidas que permiten suministrarles una legibilidad foránea. (El pueblo resiste al saber positivo, estaríamos tentados a sostener de esta lectura). No casualmente, Oyarzún cierra su intervención con una reflexión sobre la "violencia": "es preciso hablar de violencia" dice Oyarzún, "es absolutamente necesario hacerlo" y "no cabe esquive ni subterfugio". Pero "hablar de violencia" no quiere decir acá, ni en los demás textos que reflexionan sobre ella, "condenarla"; el llamado persistente del conjunto de las fuerzas de orden a "condenar la violencia" ha sido con frecuencia (y no sólo en Chile) una estrategia para ahorrarse el trabajo de pensarla. "Hablar de violencia" quiere decir acá: es necesario, imperativo, urgente, pensarla (no condenarla). Con todo, el hecho de que condenarla no sea un prerrequisito (o un chantaje) para hablar de ella (para pensarla, entonces), no quiere decir que haya que privarse de ver en ella todo su riesgo y su monstruosidad. Si la violencia es aquello que cae fuera de las formas preestablecidas de inteligibilidad, su irrupción necesariamente debe contener una comparecencia "monstruosa", fascinante y aterradora a la vez, designando esa palabra una fuga hacia zonas que carecen de forma porque la buscan a tientas.

En un nivel estrictamente conceptual, y en continuidad con un trabajo de largo aliento, el artículo de Valeria Campos vuelve sobre el problema de la violencia -sobre la "crítica de la violencia”- en relación con la representación: “¿puede una crítica de la representación ser a la vez una crítica de la violencia?" se pregunta de entrada. La respuesta de Campos a esta 
y una serie de preguntas derivadas se ofrece a través de un examen de un texto de Walter Benjamin de 1921, al que se añade a continuación la apuesta derrideana por una "archiviolencia" o "violencia originaria". Aunque estas han sido cuestiones largamente analizadas (en parte por la misma autora en trabajos previos), la propuesta se articula con un tercer conjunto de trabajos que permiten iluminar el problema desde un ángulo distinto. En el "cuarto momento" del texto, Campos desarrolla el pensamiento de Viveiros de Castro en el que la violencia es concebida como contra-violencia respecto de una archiviolencia, o violencia originaria, poniéndose en escena el problema de una "lógica 'diet-ética"” propia del caníbal: una ética de la incorporación sin asimilación.

Por último, el artículo de Hugo Tavera es el único en abordar en forma autónoma el problema de la traición, cuestión que los demás artículos y la misma convocatoria tratan en forma subordinada a la cuestión de la representación. Tavera se focaliza en este problema a partir de una lectura en profundidad del capítulo VIII de El príncipe de Maquiavelo, mostrando cómo el autor florentino es más bien "ambiguo" en relación con la traición, marcando un contrapunto manifiesto con la tradición que lo antecede, para la cual -por regla general- la traición es concebida como el "peor de los pecados". Esta ambigüedad lleva a Tavera a concluir que para Maquiavelo -y en contra de lo que se piensa a menudo- "no habría ninguna diferencia relevante entre el príncipe civil y el príncipe criminal”, esto es, de aquél que se ha hecho del poder echando mano de la traición. Esto es así porque la condición civil del príncipe vendría definida por el "tipo de relación que [aquél] establece con una de las fuerzas sociales de las que está compuesto todo cuerpo político, la multitud, el pueblo o el universal".

La situación del "octubre" chileno ha obligado a repensar una serie de categorías políticas (o estético-teológico-políticas) con las que hasta ahora veníamos haciendo comprensible los equilibrios de poder del sistema político chileno, como lo muestra el proceso constituyente en curso. Enfrentamos un momento crítico, donde "crítico" implica precisamente un esfuerzo extraordinario del pueblo chileno por pensar e imaginar de otro modo. Por la misma razón, el recurso a la historia resulta fundamental, pero a la vez no parece ser suficiente. 
El conjunto de textos acá publicados constituye un aporte a una discusión que con probabilidad tendremos a lo largo de los próximos diez años, al menos. Lejos de ser un problema de interés local -como antes lo hemos señalado-, hay una cierta lógica (y una crisis) global que está en juego en el caso chileno y su crisis. Una consigna de proporciones enormes en el centro de Santiago señalaba: "el neoliberalismo nace y muere en Chile". No es difícil atribuirle realidad a lo primero (aunque cueste creerlo, no se trata de un simple cliché), pero por la misma razón no tenemos cómo saber acerca del contenido de la lengua y de las imágenes que contendría ese nuevo mundo luego de que el actual termine de morir. Es -insistamos por última vez en ello- un trabajo del pensamiento, de la imaginación y, sin duda, de la sensibilidad (todas éstas en su dimensión colectiva) lo que terminará por confirmar o no si hemos estado a la altura de la consigna recién citada, y con respecto a la cual hemos decidido medir nuestro tiempo, nuestro krinein.

\section{Financiamiento}

La edición del presente número de Pléyade ha sido realizada en el marco del proyecto FONDECYT Postdoctoral Nro. 3180139. 


\section{Referencias bibliográficas}

Bustamante, Gonzalo. "Republicanismo y democracia agonal: una presentación genealógica. Introducción”. Pléyade 20 (2017): 17-32.

Derrida, Jacques. "Envío". En Psyché. Invenciones del otro. Buenos Aires: Ediciones La cebra, 2017.

. Prejuzgados. Ante la Ley. Madrid: Editorial Avarigani, 2011.

Foucault, Michel. “¿Qué es la crítica? [Crítica y Aufklärung]”. Daimon Revista Internacional de Filosofía 11 (1995): 5-26.

Freud, Sigmund. Civilization and Its Discontents. Ontario: Broadview Press, 2015. . “Totem y Tabú”. En Obras Completas, vol. XIII. Buenos Aires:

Editorial Amorrortu, 2008.

Hartley, George. The Abyss of Representation. Durhan: Duke University Press, 2003.

Heidegger, Martin. "La época de la imagen del mundo". En Caminos de bosque. Madrid: Editorial Alianza, 2006.

Seyhan, Azade. Representation and Its Discontents: The Critical Legacy of German Romanticism. California: University of California Press, 1992.

Thielemann, Luis. "Notas para la historia de un desencuentro en la revuelta. Sobre alianzas sociales, izquierdas y una década de luchas sociales. Chile, 2011-2020”. Revista Némesis 16 (2020): 109-119.

\section{Sobre el autor}

Diego Fernández H. Investigador postdoctoral FONDECYT-Universidad Diego Portales (Santiago, Chile). Doctor en Filosofía por la Universidad de Chile. Ha sido profesor de filosofía y estética en distintas universidades de Chile, e investigador visitante en la Universidad de Northwestern, Illinois, Estados Unidos. Ha publicado artículos y traducciones sobre estética y filosofía contemporánea, además de los libros La justa medida de una distancia: Benjamin y el romanticismo de Jena (Santiago: Orjikh, a aparecer en 2021) y el libro en edición Brillar por ausencia. Walter Benjamin y la cuestión de la verdad. Editor del libro Sobre Harun Farocki: la continuidad de la guerra a través de las imágenes 
(Santiago: Metales Pesados, 2014) y coinvestigador del proyecto FONDECYT Regular No 1191155 "Deconstrucción de lo trágico. La literatura como apuesta filosófica y política en Lacoue-Labarthe y Derrida". Correo electrónico: diegofernan@gmail.com. 